九州大学学術情報リポジトリ

Kyushu University Institutional Repository

\title{
DNA assembly and re-assembly activated by cationic comb-type copolymer
}

Mor i yama, Rui

Institute for Materials Chemistry and Engineering, Kyushu University

Shimada, Naohiko

Institute for Materials Chemistry and Engineering, Kyushu University

Kano, Arihiro

Institute for Materials Chemistry and Engineering, Kyushu University

ht tp://hdl. hand le. net/2324/25461

出版情報 : Biomaterials. 32 (9)，pp.2351-2358，2011-03. Elsevier バージョン:

権利関係: (C) 2010 Elsevier Ltd. 
DNA assembly and reassembly activated by cationic comb-type copolymer

Rui Moriyama ${ }^{a}$, Naohiko Shimada ${ }^{\mathrm{a}}$, Arihiro Kano ${ }^{\mathrm{a}}$, Atsushi Maruyama ${ }^{\mathrm{a}^{*}}$

${ }^{a}$ Institute for Materials Chemistry and Engineering, Kyushu University, 744 CE11 Motooka,

Nishi, Fukuoka 819-0395, Japan.

*Corresponding author. Institute for Materials Chemistry and Engineering, Kyushu University, 744 CE11 Motooka, Nishi, Fukuoka 819-0395, Japan.

E-mail address: maruyama@ms.ifoc.kyushu-u.ac.jp 


\begin{abstract}
Guanine-rich oligonucleotides, such as $\mathrm{TG}_{4} \mathrm{~T}$ and $\mathrm{TG}_{5} \mathrm{~T}$, assemble into a tetramolecular quadruplexes with layers of G-quartets stabilized by coordination to monovalent cations. Association rates of the quadruplexes are extremely slow, likely owing to electrostatic repulsion among the four strands. We have shown that comb-type copolymers with a polycation backbone and abundant hydrophilic graft chains form water-soluble polyelectrolyte complexes with DNA and promote DNA hybridization. Here, we report the effect of cationic comb-type copolymers on the kinetics of tetramolecular quadruplex formation. The copolymer significantly increased the association rate of tetramolecular quadruplexes without altering kinetic effects of metal cations in quadruplex formation. Dissociation rates of the quadruplexes were also accelerated by the copolymer suggesting that the copolymer has chaperone-like activity that reduces the energy barriers associated with dissociation and re-assembly of base pairs. This hypothesis was further supported by the observation that the copolymer activated the strand exchange reaction between the quadruplex and a constituting single-stranded.
\end{abstract}




\section{Introduction}

Polyelectrolytes spontaneously form inter-polyelectrolyte complexes (IPECs) with oppositely charged polyelectrolytes. IPEC formation is driven by an entropic contribution from low molecular weight counterions that are released from the vicinities of each of the polyelectrolytes upon complex formation [1]. IPEC formation usually results in a pronounced change in polymer conformation from extended coil structures to highly condensed and compacted globule structures (i.e., the coil-globule transition) [1]. Due to stability and stoichiometric properties, IPECs have been exploited in assembly of a variety of nanostructures [1-3]. For example, well-organized polyelectrolyte films [4] and capsules [5] were produced using a "layer-by-layer" deposition method. Core-shell-type nanoparticles, polyion complex micelles composed of charged block copolymers having hydrophobic polymer chains and oppositely charged polyelectrolytes, have been extensively studied and are potential carriers of DNA and therapeutic agents [6-8]. In these cases, the coil-globule transition and solubility changes play pivotal roles in assembly processes, stability, and functions.

We are interested in water-soluble IPECs formed between polycations and DNA. The cationic comb-type copolymer comprised of more than $80 \mathrm{wt} \%$ hydrophilic graft chains and less than $20 \mathrm{wt} \%$ cationic backbone gives a totally soluble IPEC with DNA, and DNA condensation (the coil-globule transition) is suppressed in the IPEC [9-11]. We showed that the copolymer 
promotes sequence-specific hybrid formation, such as formation of double-stranded DNA (dsDNA) and triple-stranded DNA (tsDNA) [9-11]. Salt concentration dependencies of hybrid stability are eliminated in the presence of the copolymer at least up to physiological salt concentration [12-18], suggesting that the copolymer shields electrostatic repulsion of the DNA strands to stabilize DNA assembly. Our kinetic study indicated that the copolymer significantly increased association rates of dsDNA and tsDNA [12-14]. Moreover, the copolymer also accelerates the strand exchange reaction between dsDNA and complementary single-stranded DNA (ssDNA) [15-19]. These observations indicate that the copolymer not only influences stability of DNA structures but also the association process. We hypothesize that the copolymer facilitates formation of transitional complexes, like double-stranded or triple-stranded nucleation complexes, by increasing simultaneous multi-molecular collision of negatively charged strands and stabilizing these complexes with high anionic charge densities.

G-quadruplex DNA is of interest due to recent demonstrations of its biological relevance and to applications in nano-biotechnology [20]. Well-defined nanoconstructs such as DNA nanowire [21], frayed wire [22] and synapsed wire [23] were designed using G-quadruplexes as a building block. Robust DNA-fueled DNA nanomachines were also created [24,25]. Quadruplexes were also found in several aptamers such as thrombin-binding aptamer [26] and anticancer aptamer [27], implicated that quadruplex structures could be a potential scaffold to 
acquire functional DNAs. Guanine-rich sequences can fold into G-quadruplexes that are stabilized by specific coordination of certain metal ions such as $\mathrm{Na}^{+}$or $\mathrm{K}^{+}[20]$. Certain, short DNA oligomers adopt well-characterized quadruplex structures. For example, $\mathrm{TG}_{4} \mathrm{~T}$ assembles into a tetramolecular quadruplex, $\left[\mathrm{TG}_{4} \mathrm{~T}\right]_{4}$, consisting of four parallel strands stabilized by four layers of G-quartets [28-30]. Several quadruplex formation pathways have been described, including stepwise strand assembly with dimer intermediates [31-33] and simultaneous association of four strands $[34,35]$. Whatever the mechanism, the electrostatic repulsion resulting from bringing together four negatively charged strands presumably results in the extremely slow kinetics of quadruplex formation. Formation of mismatched quadruplexes that competes assembling into fully-matched canonical quadruplex was also suggested to explain the slow assembly [33]. Once the mismatched quadruplexes are formed, spontaneous re-assembly into fully matched quadruplexes must be slow because of the very slow dissociation kinetics of quadruplexes.

We hypothesized that cationic comb-type copolymers could promote the quadruplex assembly by reducing the electrostatic repulsion among the strands and/or by facilitating transformation to the canonical quadruplex from the mismatched quadruplexes through catalysis of strand exchange. We are also interested in how highly multivalent ionic interactions between the cationic copolymer and DNA influences DNA assembly that involves specific 
coordination of monovalent cations, such as $\mathrm{Na}^{+}$and $\mathrm{K}^{+}$. In this study, we evaluated kinetic effects of a cationic comb-type copolymer, poly(L-lysine)-graft-dextran copolymer (PLL-g-Dex, Figure 1), on assembly and strand exchange of the quadruplex, and discussed the activities of the copolymer in relation to a nucleic acid chaperone.

\section{Materials and methods}

\subsection{Materials}

PLL $\cdot \mathrm{HCl}\left(\mathrm{M}_{\mathrm{W}}=5.3 \times 10^{4}\right)$ and dextran T-10 $\left(\mathrm{M}_{\mathrm{W}}=8.4 \times 10^{3}\right)$ were obtained from Peptide Institute. Inc. (Osaka, Japan) and Pharmacia Biotechnology (Uppsala, Sweden), respectively. Sodium hydroxide, boric acid, sodium sulfate, and acetic acid were purchased from Wako Pure Chemical Industries (Osaka, Japan). Sodium tetraborate decahydrate was obtained from Nacali Tesque, Inc. (Kyoto, Japan). An oligonucleotide with the sequence 5'-TGGGGT-3' $\left(\mathrm{TG}_{4} \mathrm{~T}\right)$ and TAMRA-labeled $\mathrm{TG}_{4} \mathrm{~T}\left(\mathrm{~F}^{-} \mathrm{TG}_{4} \mathrm{~T}\right)$ were purchased from GeneNet Co. Ltd. (Fukuoka, Japan) and FASMAC Co. Ltd. (Tokyo, Japan), respectively. Preparation of the quadruplex $\left[\mathrm{TG}_{4} \mathrm{~T}\right]_{4}$ was performed as follows: $\mathrm{TG}_{4} \mathrm{~T}(1 \mathrm{mM})$ was heated to $90{ }^{\circ} \mathrm{C}$ and then slowly cooled to $4{ }^{\circ} \mathrm{C}$ in $10 \mathrm{mM}$ PBS (pH 7.2), $100 \mathrm{mM} \mathrm{NaCl}$. After the $\mathrm{TG}_{4} \mathrm{~T}$ solution was incubated for 7 days at $4{ }^{\circ} \mathrm{C}$, the $\left[\mathrm{TG}_{4} \mathrm{~T}\right]_{4}$ stock solution was stored at $-20{ }^{\circ} \mathrm{C}$. 


\section{2 Preparation of PLL-g-Dex copolymers}

PLL-g-Dex was prepared by reductive animation reaction between PLL and Dex as described in a previous report [9-11]. The obtained PLL-g-Dex was isolated using a column packed with TOYOPERAL CM-650C weakly cationic exchange resin (TOSOH, Tokyo, Japan). The column was equilibrated with $0.1 \mathrm{M}$ sodium borate buffer ( $\mathrm{pH}$ 8.5) and PLL-g-Dex was eluted with $1 \mathrm{M}$ acetic acid containing $0.5 \mathrm{M} \mathrm{Na}_{2} \mathrm{SO}_{4}$. The polymer fraction was dialyzed against water and lyophilized. PLL- $g$-Dex was characterized by NMR and gel permeation chromatography (GPC) measurements.

\section{3 Thermal denaturation and renaturation in the absence or presence of copolymer}

Thermal denaturation and renaturation curves of the tetramolecular quadruplex were obtained by heating/cooling experiments. Various concentrations of $\left[\mathrm{TG}_{4} \mathrm{~T}\right]_{4}$ solution in 10 mM PBS (pH 7.2) containing $100 \mathrm{mM} \mathrm{NaCl}$ with (N/P =2) or without PLL-g-Dex were heated at a rate of $1{ }^{\circ} \mathrm{C} / \mathrm{min}$ from 20 to ca. $90{ }^{\circ} \mathrm{C}$ (and vice versa). The $\mathrm{CD}$ signals at $263 \mathrm{~nm}$ of $\left[\mathrm{TG}_{4} \mathrm{~T}\right]_{4}$ were recorded as a function of temperature in quartz optical cells of $0.1-\mathrm{mm}$ to $10-\mathrm{mm}$ path length. 
$\mathrm{TG}_{4} \mathrm{~T}$ in $10 \mathrm{mM}$ PBS (pH 7.2) was incubated for $10 \mathrm{~min}$ at $90{ }^{\circ} \mathrm{C}$. After cooling to reaction temperatures ranging from 4 to $30^{\circ} \mathrm{C}, \mathrm{PLL}-g$-Dex $(\mathrm{N} / \mathrm{P}=0$ to 8$)$ or PLL $(\mathrm{N} / \mathrm{P}=4)$ and $\mathrm{NaCl}$ or $\mathrm{KCl}$ (final concentration $100 \mathrm{mM}$ ) was added. The $\mathrm{CD}$ spectra or molar ellipticity at $263 \mathrm{~nm}$ of the solution (initial concentrations of $\mathrm{TG}_{4} \mathrm{~T}$ : $10-200 \mu \mathrm{M}$ ) were recorded. The quadruplex dissociation kinetics were determined as follows: The $\left[\mathrm{TG}_{4} \mathrm{~T}\right]_{4}$ stock solution was diluted with $10 \mathrm{mM}$ PBS ( $\mathrm{pH}$ 7.2) containing $100 \mathrm{mM} \mathrm{NaCl}$ (final concentration of $\mathrm{TG}_{4} \mathrm{~T}_{4}=30$ $\mu \mathrm{M})$ with $(\mathrm{N} / \mathrm{P}=2)$ or without PLL- $g$-Dex at $45-60{ }^{\circ} \mathrm{C}$. Molar ellipticity changes at $263 \mathrm{~nm}$ of $\mathrm{TG}_{4} \mathrm{~T}$ were collected.

\section{5 Determination of association kinetics of quadruplex by gel electrophoresis}

$\mathrm{TG}_{4} \mathrm{~T}$ (final concentration: $200 \mu \mathrm{M}$ ) in $10 \mathrm{mM}$ PBS (pH 7.2) without $\mathrm{NaCl}$ was incubated for $10 \mathrm{~min}$ at $90^{\circ} \mathrm{C}$. After cooling to $20^{\circ} \mathrm{C}$, a cationic polymer (PLL-g-Dex or PLL, $\mathrm{N} / \mathrm{P}=4$ ) and $\mathrm{NaCl}$ (final concentration $100 \mathrm{mM}$ ) were added. After the incubation at $20{ }^{\circ} \mathrm{C}$ for the indicated time periods, DNAs were separated by $20 \%$ polyacryamide gels. The quadruplexes were stained by EtBr. A fluorescence image of the gel was obtained with a Fujifilm LAS-3000 luminescent image analyzer (Tokyo, Japan). 


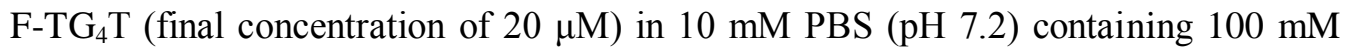
$\mathrm{NaCl}$ with (final N/P = 2) or without PLL- $g$-Dex was added to $\left[\mathrm{TG}_{4} \mathrm{~T}\right]_{4}$ (final concentration of $55 \mu \mathrm{M})$ solution in the same buffer. The mixture was incubated at $25^{\circ} \mathrm{C}$ for various time periods. After the incubation, the mixture was placed in an ice bath and excess polyvinyl sulfate (PVS) was added to dissociate PLL-g-Dex from DNA. The mixtures were separated by gel electrophoresis at $100 \mathrm{~V}$ on a $20 \%$ polyacrylamide gel at $4{ }^{\circ} \mathrm{C}$ in $1 \times \mathrm{TBE}$ buffer. $\mathrm{A}$ fluorescence image of the gel was obtained with a Fujifilm LAS-3000 luminescent image analyzer (Tokyo, Japan). The degree of strand exchange in percent was calculated using equation (1):

$$
\% \text { Exchange degree }=\frac{\left([\mathrm{FI}]_{t}-[\mathrm{FI}]_{0}\right)}{\left([\mathrm{FI}]_{t}-[\mathrm{FI}]_{0}\right)}
$$

Where, $[\mathrm{FI}]_{t},[\mathrm{FI}]_{0}$, and $[\mathrm{FI}]_{\infty}$ are fluorescence intensities of strand exchanged tetramolecular quadruplex at time $t$, at the initial time, and after the reaction reached equilibrium, respectively. $[\mathrm{FI}]_{\infty}$ was obtained by heating the mixture at $90{ }^{\circ} \mathrm{C}$ for $5 \mathrm{~min}$, followed by slow cooling and a week incubation at $4{ }^{\circ} \mathrm{C}$.

2. 7 DNA binding to copolymer as determined by fluorescence correlation spectroscopy

Binding of DNA to the copolymer was assessed by fluorescence correlation spectroscopy [18,36,37] using an Olympus MF20 single-molecular fluorescence detection 
system (Olympus, Tokyo Japan). All samples for the fluorescence correlation spectroscopy measurements were prepared in $10 \mathrm{mM}$ PBS (pH 7.2) containing $100 \mathrm{mM} \mathrm{NaCl}$ and the DNA

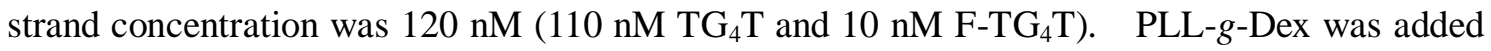
to the DNA sample at concentrations ranging from 0 to $200 \mu \mathrm{M}$; the PLL-g-Dex concentration was determined based on the lysine residues. An aliquot $(50 \mu \mathrm{M})$ of each sample was transferred to a 384-well microplate. A standard solution of $1 \mathrm{nM}$ RITC in the same buffer was used to derive optical parameters necessary for a proper measurement. A He-Ne laser $\left(\lambda_{\mathrm{exc}}=543 \mathrm{~nm}\right)$ was set at $200 \mu \mathrm{W}$. All measurements were carried out in at least duplicate and four scans of each sample were taken, each lasting $10 \mathrm{~s}$ at room temperature. The obtained data were fitted according to an autocorrelation function in the instrument software. Each data point was mean value of the measured samples. The measurements of tetramolecular quadruplex were also conducted under the same conditions.

\section{Result}

3. 1 Effect of PLL-g-Dex on thermal dissociation and association of tetramolecular quadruplex

We evaluated the effects of PLL- $g$-Dex (Mw of PLL backbone: $5.3 \times 10^{4}, \mathrm{Mw}$ of dextran grafts: $8.4 \times 10^{3}$, drafting degree of dextran: 16.2 mole\%) on the 
thermal dissociation and re-association of intermolecular quadruplexes by temperature-gradient CD measurements. As shown in Figure 2a, melting of $\left[\mathrm{TG}_{4} \mathrm{~T}\right]_{4}$ quadruplex was detected as a decrease in CD signal at $263 \mathrm{~nm}$ as the temperature was increased. In the absence of the copolymer, considerable hysteresis between the heating and cooling curves was observed [33]. This is indicative of the slow association kinetics of the $\left[\mathrm{TG}_{4} \mathrm{~T}\right]_{4}$ intermolecular quadruplex that has been previously described $[31,33]$. In the presence of the copolymer, nearly reversible heating and cooling profiles were obtained, suggesting that the copolymer accelerated the association kinetics of the quadruplex. Figure $2 \mathrm{~b}$ shows the relationship between $\mathrm{TG}_{4} \mathrm{~T}$ concentration and the midpoint of the melting transition $\left(T_{1 / 2}\right)$ determined from the heating scans. In the absence of the copolymer, the DNA concentration dependency of $T_{1 / 2}$ was not significant as expected due to the slow association kinetics; this is consistent with a previous report [33]. In the presence of the copolymer, $T_{1 / 2}$ increased with increasing $\mathrm{TG}_{4} \mathrm{~T}$ concentration, indicating that the copolymer accelerated quadruplex assembly. Note that $T_{1 / 2}$ values obtained in the presence of the copolymer were lower than in the absence of the copolymer over the $\mathrm{TG}_{4} \mathrm{~T}$ concentration range of 10 to $100 \mu \mathrm{M}$. This result suggests that the copolymer accelerates not only the association but also the dissociation of the tetramolecular quadruplex. 
We next assessed effect of the copolymer on association of the tetramolecular quadruplex at constant temperature. Figure 3 a shows the $\mathrm{CD}$ spectra of $\mathrm{TG}_{4} \mathrm{~T}(30 \mu \mathrm{M}$ strand) in the absence and presence of the copolymer as a function of time. In the absence of the copolymer, 50\% quadruplex formation required $5800 \mathrm{~min}$ (ca. 4 days) in qualitative agreement with previous reports [33]. In contrast, in the presence of the copolymer, the quadruplex CD signal appeared within a few minutes and only 10 min incubation was required to achieve $50 \%$ quadruplex formation. The Fourth order rate constants, $k_{\mathrm{on}}$, were estimated from changes in CD signal at $263 \mathrm{~nm}$ over time (Figure S1). These data are plotted as a function of the N/P ratio in Figure 3b. In the absence of the copolymer, the $k_{\text {on }}$ at $4^{\circ} \mathrm{C}$ with $100 \mathrm{mM} \mathrm{NaCl}$ was $3.1 \times 10^{8}$ $\mathrm{M}^{-3} \sec ^{-1}$, consistent with a previous report [33]. In the presence of the copolymer, the $k_{\mathrm{on}}$ increased linearly with increasing $\mathrm{N} / \mathrm{P}$ ratio and reached a plateau at $\mathrm{N} / \mathrm{P}=2$. At $\mathrm{N} / \mathrm{P}=2, k_{\text {on }}$ was $2.8 \times 10^{11} \mathrm{M}^{-3} \mathrm{sec}^{-1}$, indicating a nearly 1000 -fold acceleration of quadruplex assembly in the presence of the copolymer. Since kinetic study with CD measurements could be affected by complicated assembling processes, such as different pathways and conformations, of quadruplex formation [31-35], the association kinetics of tetramolecular quadruplexes at $200 \mu \mathrm{M} \mathrm{TG} 4$ were further estimated by gel electrophoresis assay (Figure 4). The results comparable to the $\mathrm{CD}$ measurement were obtained. Whereas only $40 \%$ quadruplex formation was observed after 240 min incubation in the absence of the copolymer, $>80 \%$ quadruplex 
formation was observed within 10 min incubation in the presence of the copolymer (Figure 4a and 4c). Note that poly(L-lysine) homopolymer hardly accelerates the quadruplex assembly (Figures $4 \mathrm{~b}$ ). It was also shown by CD study that dextran even at high concentration did not accelerate the quadruplex association (Figure S1).

The tetramolecular quadruplex assembly is faster in a potassium buffer than in a sodium buffer [33, 34]. The $k_{\text {on }}$ value in $100 \mathrm{mM} \mathrm{KCl}$ was estimated at $1.2 \times 10^{10} \mathrm{M}^{-3} \mathrm{sec}^{-1}$, implying 40-fold faster assembling than that in $100 \mathrm{mM} \mathrm{NaCl}$. In our hands, the copolymer further increased $k_{\text {on }}$ in $100 \mathrm{mM} \mathrm{KCl}$ (Figure 3c). At $\mathrm{N} / \mathrm{P}=2$, the $k_{\text {on }}$ was $5.0 \times 10^{12} \mathrm{M}^{-3} \mathrm{sec}^{-1}$ in $100 \mathrm{mM}$ potassium. This data is summarized in Table 1. These results suggest that the multivalent ionic interactions between the copolymer and DNA did not significantly modify the kinetic effects of monovalent ions.

We then evaluated temperature dependency of the quadruplex assembly. Consistent with previous reports [33], the $k_{\mathrm{on}}$ values decreased with increasing temperature in the absence of the copolymer (Figure 3d). The negative temperature dependency is consistent with a nucleation-zippering mechanism for strand association [33, 38]. The negative temperature dependency was also observed in the presence of the copolymer.

The effect of the copolymer on the quadruplex dissociation kinetics is shown in Figure 5. The copolymer moderately increased the dissociation rate in an N/P ratio dependent manner. 
At N/P > 2, the dissociation rate increased by at least 6 -fold at $60^{\circ} \mathrm{C}$ relative to the rate in the absence of copolymer. Thus, the copolymer increased both the association and dissociation rates of quadruplex, suggesting that the copolymer has a catalytic effect of reducing the energy barriers needed for dissociation and association of nucleic acid structures, as do nucleic acid chaperones $[39,40]$.

\section{3 Evaluation of strand exchange reaction between tetramolecular quadruplex and ssDNA}

One of unique features of nucleic acid chaperones is their ability to catalyze a strand exchange reaction. For example, a native nucleic acid chaperone, the nucleocapsid protein expressed by retroviruses, facilitates the strand exchange reaction between dsDNA and homologous single strands by reducing the energy barrier for dissociation and association of base pairing $[39,40]$. To examine the ability of the copolymer to serve as a quadruplex chaperone, its influence on the strand exchange reaction between a $\left[\mathrm{TG}_{4} \mathrm{~T}\right]_{4}$ quadruplex and a $\mathrm{TG}_{4} \mathrm{~T}$ strand was assessed (Scheme 1). In order to monitor strand exchange, fluorescently labeled $\mathrm{TG}_{4} \mathrm{~T}$ $\left(\mathrm{F}-\mathrm{TG}_{4} \mathrm{~T}\right.$ ) was incubated at $25^{\circ} \mathrm{C}$ with an excess amount (a 2.5 -fold molar excess based on strand concentration) of pre-formed $\left[\mathrm{TG}_{4} \mathrm{~T}\right]_{4}$ quadruplexes. At indicated times, the reaction mixtures were analyzed by PAGE. As shown in Figure 6a, no strand exchange product, $\left[\left(\mathrm{TG}_{4} \mathrm{~T}\right)_{3} \cdot \mathrm{F}-\mathrm{TG}_{4} \mathrm{~T}\right]$, was detected in the reaction mixture without the copolymer. In the presence of the copolymer 
$(\mathrm{N} / \mathrm{P}=4)$, increasing amounts of the strand-exchange product (upper bands in Figure 6a) appeared in a time-dependent manner. After $180 \mathrm{~min}, 65 \%$ of $\left[\mathrm{TG}_{4} \mathrm{~T}\right]_{4}$ contained $\mathrm{F}-\mathrm{TG}_{4} \mathrm{~T}$ (Figure 6b); our assumption was that only a single fluorescein-tagged strand was incorporated per quadruplex. The copolymer activated the strand exchange reaction in an N/P ratio dependent manner and the activation effect reached a plateau at an $\mathrm{N} / \mathrm{P}$ of 4 . Incubation of $\mathrm{F}-\mathrm{TG}_{4} \mathrm{~T}$, without $\left[\mathrm{TG}_{4} \mathrm{~T}\right]_{4}$, in the presence of the copolymer resulted in negligible quadruplex formation (Figure S5), indicating a slight influence of $\left[\mathrm{F}-\mathrm{TG}_{4} \mathrm{~T}\right]_{4}$ quadruplex formation on the strand exchange reaction assay.

\section{4 Binding assay of the copolymer to ssDNA and tetramolecular quadruplex DNA}

To further understand the effect of the copolymer, binding of copolymer to either ssDNA or tetramolecular quadruplex DNA was analyzed by fluorescence correlation spectroscopy $[18,36,37]$. Since a diffusion time calculated by the autocorrelation analysis of the fluorescence fluctuation is proportional to cubic root of molecular mass, the complex formation of oligonucleotides with the copolymer leads to an increased in the diffusion time. Figure 7 shows the fluorescence correlation spectroscopy results for the copolymer binding with either $\mathrm{TG}_{4} \mathrm{~T}$ or $\left[\mathrm{TG}_{4} \mathrm{~T}\right]_{4}$. The diffusion times of $\mathrm{TG}_{4} \mathrm{~T}$ and $\left[\mathrm{TG}_{4} \mathrm{~T}\right]_{4}$ increased with increasing copolymer concentration. The $K_{\mathrm{d}}$ value for the copolymer binding to TG4T strand was 
estimated as about $48 \mathrm{nM}$ in strand concentration $\left(20 \mu \mathrm{M}\right.$ in lysine units); that to $\left[\mathrm{TG}_{4} \mathrm{~T}\right]_{4}$ quadruplex was estimated as $<1 \mathrm{nM}(0.5 \mu \mathrm{M}$ in lysine units). Though accurate estimation of $K_{\mathrm{d}}$ value for $\left[\mathrm{TG}_{4} \mathrm{~T}\right]_{4}$ could not be accomplished owing to the detection limits of assay, the copolymer has at least 40 -fold stronger affinity to $\left[\mathrm{TG}_{4} \mathrm{~T}\right]_{4}$ quadruplex than to a $\mathrm{TG}_{4} \mathrm{~T}$ monomer. The stronger affinity of the copolymer to the quadruplex was attributed to larger number and higher charge density of phosphate anions in the quadruplex structure than in the $\mathrm{TG}_{4} \mathrm{~T}$ monomer. Our kinetic studies of $\left[\mathrm{TG}_{4} \mathrm{~T}\right]_{4}$ quadruplex assembly were carried out at DNA concentration of $30 \mu \mathrm{M}$; therefore, in our assays, both $\mathrm{TG}_{4} \mathrm{~T}$ and $\left[\mathrm{TG}_{4} \mathrm{~T}\right]_{4}$ were associated with the copolymer to form complexes at N/P $>1$.

\section{Discussion}

A yeast telomere binding protein, the $\beta$-subunit of Oxytricha telomere binding protein, and histone $\mathrm{H} 1$ are known all to accelerate the quadruplex formation [41-43]; for example, the $\beta$-subunit of Oxytricha telomere binding protein enhances the quadruplex formation of 5'-TTTTGGGGTTTTGGGG-3' by $10^{5}-10^{6}$ folds [43]. However, the effects of the proteins on quadruplex dissociation and, more particularly, on the strand exchange reaction have not been described. Recently, quadruplex ligands that increase association rate and decrease dissociation 
rate of intermolecular quadruplex formation and stabilize quadruplex structures have been reported [44].

In this study we showed that a cationic comb-type copolymer not only increased the rate of association but also dissociation rates of tetramolecular quadruplexes. The copolymer also promoted the strand exchange reaction. Thus, the copolymer has a nucleic acid chaperone-like activity. The strong electrostatic repulsion among the four strands of the quadruplex may explain the extremely slow association rates of tetramolecular quadruplexes. The copolymer likely reduces this electrostatic repulsion and stabilizes the multi-stranded transitional complex to facilitate assembly. Our previous observation that the copolymer considerably stabilizes duplex and triplex DNAs supports this hypothesis [9-11]. Formation of mismatched quadruplexes was recently suggested to be another reason for slow assembly into the fully-matched quadruplex structures $[34,35]$.

Previously we showed that the copolymer activated the strand exchange reaction between double-stranded DNA and a homologous single strand $[15,17]$. In this study, we demonstrated that the copolymers also activated strand exchange between quadruplex and single strand. Two distinct reaction pathways, a dissociative pathway and a sequential displacement pathway, have been considered for the strand exchange reaction between dsDNA and a homologous single strand $[45,46]$. Although the strand exchange reaction in the quadruplex might occur through 
the spontaneous and complete dissociation of quadruplex followed by re-assembly (Scheme 2a), the dissociation of quadruplex is very slow (with a half dissociation time of more than 100 days under our experimental conditions) and therefore this pathway cannot account for our observations. In contrast to the complete dissociation pathway, the sequential displacement pathway (Scheme 2c) requires only local melting to allow for the formation of a branched nucleation complex with a single-stranded counterpart. Subsequent migration of the branch point would result in formation of an exchanged quadruplex. The copolymer may stabilize more the branched nucleation complex that bears higher negative charges and local charge density than the quadruplex, leading to the observed rate acceleration compared to strand exchange in the absence of copolymer. In addition to the sequential displacement pathway, a partial dissociative pathway (Scheme 2b) may be possible; step-wise strand association into duplex and triplex intermediates has been proposed for quadruplex formation [32, 34].

DNA assembly is thermodynamically and kinetically influenced by the counterion condensation effect [47]. Valency, size, and shape of counterions influence the magnitude of the counterion condensation effect $[48,49]$. The copolymer forms an inter-polyelectrolyte complex with DNA through ion exchange process with $\mathrm{Na}^{+}$or $\mathrm{K}^{+}$ions that were associated with DNA. The counterion replacement of monovalent counterions with the polycationic copolymer with larger ionic multivalency likely has a strong influence on the assembly of 
polyanionic DNA and dynamics of base pairing. As others have shown, we observed differential kinetic effects of monovalent cations $\mathrm{Na}^{+}$vs. $\mathrm{K}^{+}$. The same effect was observed even in the presence of the copolymer. Regardless of the strong ionic interactions between the cationic copolymer and DNA ( $K_{\mathrm{d}}$ values for the copolymer binding to $\mathrm{TG}_{4} \mathrm{~T}$ and $\left[\mathrm{TG}_{4} \mathrm{~T}\right]_{4}$ were $48 \mathrm{nM}$ and $<1 \mathrm{nM}$, respectively), coordinating interactions of metal ions to G-quartet structures are not significantly changed. These characteristics allowed additive kinetic effects of $\mathrm{K}^{+}$and the copolymer, leading to $10^{4}$-fold increased in $k_{\mathrm{on}}$ as shown in Table 1.

\section{Conclusion}

We have shown that a cationic comb-type copolymer increases the association and dissociation rates of tetramolecular quadruplexes. Furthermore, the copolymer activated the strand exchange reaction between tetramolecular quadruplex and a single strand, suggesting that the copolymer has chaperone-like activity that reduces the energy barriers associated with dissociation and re-assembly of G-quartets. Though mechanisms underlying acceleration effect of the copolymer on dissociation, association, and strand exchange of DNA assemblies are not fully understood, the copolymer may expand 
the their utility, especially to the formation of devices that require rapid assembly and/or recombination platforms.

\section{Acknowledgements}

This research was supported by the Joint Project for Materials Chemistry, the Global COE

Program "Science for Future Molecular Systems" from the Ministry of Education, Science,

Sports, and Culture of Japan, the Grant-in-Aid (20240049), SENTAN from Japan Science and

Technology Agency, and A3 Foresight Program from the Japan Society for the Promotion of Science. 
Reference

[1] Thünemann AF, Müller M, Dautzenberg H, Joanny JF, Löwen H. Polyelectrolyte complexes. Adv Polym Sci. 2004; 166: 113-71.

[2] Hartig SM, Greene RR, DasGupta MM, Prokop A, Davidson JM. Multifunctional nanoparticulate polyelectrolyte complexes. Pharm Res. 2007; 24: 2353-69.

[3] Gröhn F. Electrostatic self-assembly as route to supramolecular structures. Macromol Chem Phys. 2008; 209: 2295-301.

[4] Picart C. Polyelectrolyte multilayer films : from physico-chemical properties to the control of cellular processes. Curr Med Chem. 2008; 15: 685-97.

[5] Pilar GR, del Mercato LL, Pino PD, JavieraAM, Park WJ. Nanoparticle-modified polyelectrolyte capsules. Nano today. 2008; 3: 12-21.

[6] Kwon G, Naito M, Yokoyama M, Okano T, Sakurai Y, Kataoka K. Micelles based on $\mathrm{AB}$ block of copolymers of poly(ethylene oxide) and poly( $\beta$-benzyl L-aspartate). Langmuir. 1993; 9: 945-9. 
[7] Katayose S, Kataoka K. Remarkable increase in nuclease resistance of plasmid DNA through supramolecular assembly with poly(ethylene glycol)-poly(L-lysine) block copolymer. J Pharm Sci. 1998; 87: 160-3.

[8] Kabanov AV, Kabanov VA. Interpolyelectrolyte and block ionomer complexes for gene delivery: physico-chemical aspects. Adv Drug Deliver Rev. 1998; 30: 49-60.

[9] Maruyama A, Katoh M, Ishihara T, Akaike T. Comb-type polycations effectively stabilize DNA triplex. Bioconjugate Chem. 1997; 8: 3-6.

[10] Maruyama A, Watanabe $H$, Ferdous A, Katoh $M$, Ishihara $T$, Akaike $T$. Characterization of interpolyelectrolyte complexes between double-stranded DNA and polylysine comb-type copolymers having hydrophilic side chains. Bioconjugate Chem. 1998; 9: 292-9.

[11] Sato Y, Kobayashi Y, Kamiya T, Watanabe H, Akaike T, Yoshikawa K et al. The effect of backbone structure on polycation comb-type copolymer/DNA interactions and the molecular assembly. Biomaterials. 2005; 26: 703-711. 
[12] Torigoe H, Ferdous A, Watanabe H, Akaike T, Maruyama A. Poly

(L-lysine)-graft-dextran copolymer promotes pyrimidine motif triplex DNA formation at physiological pH. Thermodynamic and kinetic stadies. J Biol Chem. 1999; 274: 6161-7.

[13] Wu L, Shimada N, Kano A, Maruyama A. Poly(L-lysine)-graft-dextran copolymer accelerates DNA hybridization by two orders. Soft Matter. 2008; 4: 744-7.

[14] Torigoe H, Maruyama A, Obika S, Imanishi T, Katayama T. Synergistic stabilization of nucleic acid assembly by $2^{\prime}-O, 4^{\prime}-C$-methylene-bridged nucleic acid modification and additions of comb-type cationic copolymers. Biochemistry. 2009; 48: 3545-3553.

[15] Kim WJ, Ishihara T, Akaike T, Maruyama A. Comb-type cationic copolymer expedites DNA strand exchange while stabilizing DNA duplex. Chem Eur J. 2001; 7: 176-180.

[16] Kim WJ, Sato Y, Akaike T, Maruyama A. DNA strand exchange stimulated by spontaneous complex formation with cationic comb-type copolymer. J Am Chem Soc. 2002; 124: $12676-7$.

[17] Kim WK, Sato Y, Akaike T, Maruyama A. Cationic comb-type copolymers for DNA analysis. Nat Mater. 2003; 2: 815-20. 
[18] Choi SW, Kano A, Maruyama A. Activation of DNA strand exchange by cationic comb-type copolymers: effect of cationic moieties of the copolymers. Nucleic Acids Res. 2008; 36: $342-51$.

[19] Choi SW, Makita N, Inoue S, Lesoi IC, Yamayoshi A, Kano A et al. Cationic comb-type copolymers for boosting DNA-fueled nanomachines. Nano Lett. 2007; 7: 172-8.

[20] Davis JT. G-quartets 40 years later: from 5'-GMP to molecular biology and supramolecular chemistry. Angew Chem Int Ed. 2004; 43: 668-98.

[21] Marsh TC, Henderson E. G-wires: self-assembly of a telomeric oligonucleotide, d(GGGGTTGGGG), into large superstructures. Biochemistry. 1994; 33(35):10718-24.

[22] Protozanova E, Macgregor RB Jr. Frayed wires: a thermally stable form of DNA with two distinct structural domains. Biochemistry. 1996; 35: 16638-45.

[23] Fahlman RP, Sen D. Cation-regulated self-association of "synapsable" DNA duplexes. J Mol Biol. 1998; 280: 237-44.

[24] Alberti R, Mergny JL. DNA duplex-quadruplex exchange as the basis for a nanomolecular machine. Proc Natl Acad Sci USA. 2003; 100: 1569-73. 
[25] Zhao C, Song Y, Ren J, Qu X. A DNA nanomachine induced by single-walled carbon nanotubes on gold surface. Biomaterials. 2009; 30: 1739-45.

[26] Dapić V, Abdomerović V, Marrington R, Peberdy J, Rodger A, Trent JO et al. Biophysical and biological properties of quadruplex oligodeoxyribonucleotides. Nucleic Acids res. 2003; 31(8): 2097-107.

[27] Bates PJ, Kahlon JB, Thomas SD, Trent JO, Miller DM. Antiproliferative activity of G-rich oligonucleotides correlates with protein binding. J Biol Chem. 1999; 274(37): 26369-77.

[28] Gehring K, Leroy JL, Guéron M. A tetrameric DNA structure with protonated cytosine.cytosine base pairs. Nature. 1993;363: 561-5.

[29] Aboul-ela F, Murchie AI, Norman DG, Lilley DM. Solution structure of a parallel-stranded tetraplex formed by $\mathrm{d}(\mathrm{TG} 4 \mathrm{~T})$ in the presence of sodium ions by nuclear magnetic resonance spectroscopy. J Mol Biol. 1994; 243(3): 458-71.

[30] Laughlan G, Murchie AI, Norman DG, Moore MH, Moody PC, Lilley DM, Luisi B. The high-resolution crystal structure of a parallel-stranded guanine tetraplex. Science. 1994; 265: 520-4. 
[31] Wyatt JR, Davis PW, Freier SM. Kinetics of G-quartet-mediated tetramer formation.

Biochemistry. 1996; 35; 8002-8.

[32] Stefl R, Cheatham TE, Spackova N, Fadrna E, Berger L, Koca J et al. Formation pathways of a guanine-quadruplex DNA revealed by molecular dynamics and thermodynamical analysis of the substates. Biophys J. 2003; 85: 1787-804.

[33] Mergny JL, De Cian A, Ghelab A, Saccá B, Lacroix L. Kinetics of tetramolecular quadruplexes. Nucleic Acids Res. 2005; 33: 81-94.

[34] Bardin C, Leroy JL. The formation pathway of tetramolecular G-quadruplexes. Nucleic Acids Res. 2008; 36: 477-88.

[35] Rosu F, Gabelica V, Poncelet H, De Pauw E. Tetramolecular G-quadruplex formation pathways studied by electrospray mass spectrometry. Nucleic Acids Res. 2010; 1-6.

[36] Elson EL, Madge D. Fluorescence correlation spectroscopy. I. Conceptual basis and theory. Biopolymers. 1974; 13: 1-27.

[37] Hess ST, Huang S, Heikal AA, Web WW. Biological and chemical applications of fluorescence correlation spectroscopy. Biochemistry. 2002; 41: 697-705. 
oligoribouridylic-oligoriboadenylic acid system and of oligoriboadenylic acid alone at acidic $\mathrm{pH}$.

J Mol Biol. 1971; 62: 361-81.

[39] Herschlag D. RNA chaperones and the RNA folding problem. J Biol Chem. 1995; 36: 20871-4.

[40] Rein A, Henderson LE, Levin JG. Nucleic-acid-chaperone activity of retroviral nucleocapsid proteins: significance for viral replication. TIBS. 1998; 23: 297-301.

[41] Fang G, Cech TR. The beta subunit of Oxytricha telomere binding protein promotes G-quartet formation by telomeric DNA. Cell. 1993; 74: 875-85.

[42] Giraldo R, Suzuki M, Chapman L, Rhodes D. Promotion of parallel DNA quadruplexes by a yeast telomere binding protein: a circular dichroism study. Proc Natl Acad Sci USA. 1994; 91: 7658-62.

[43] Fang G, Cech TR. Characterization of a G-quartet formation reaction promoted by the beta-subunit of the Oxytricha telomere-binding protein. Biochemistry. 1993; 32: 11646-57.

[44] De Cian A, Mergny JL. Quadruplex ligands may act as molecular chaprones for tetramolecular quadruplex formation. Nucleic Acids Res. 2007; 35: 2483-93. 
[45] Broker TR, Lehman IR. Branched DNA molecules: intermediates in T4 recombination. J Mol Biol. 1971; 60: 131-49.

[46] Reynaldo LP, Vologodskii AV, Neri BP, Lyamichev VI. The kinetics of oligonucleotide replacements. J Mol Biol. 2000; 297: 511-20.

[47] Manning GS. Limiting laws and counterion condensation in polyelectrolyte solutions I. colligative properties. J Chem Phys. 1969; 51: 924-33.

[48] Record MT. Effects of $\mathrm{Na}^{+}$and $\mathrm{Mg}^{2+}$ ions on the helix-coil transition of DNA. Biopolymers. 1975; 14: 2137-58.

[49] Heilman-Miller SL, Pan J, Thirumalai D, Woodson SA. Role of counterion condensation in folding of the tetrahymena ribozyme. II. counterion-dependence of folding kinetics. J Mol Biol. 2001; 309: 57-68. 
Table 1

The association rate constants of $\left[\mathrm{TG}_{4} \mathrm{~T}\right]_{4}$ quadruplex in $100 \mathrm{mM} \mathrm{Na}^{+}$or $\mathrm{K}^{+}$buffer with or without PLL- $g$-Dex $(\mathrm{N} / \mathrm{P}=2)$.

\begin{tabular}{ccc}
\hline & \multicolumn{2}{c}{$k_{\text {on }} / \mathrm{M}^{-3} \mathrm{sec}^{-1}$} \\
\cline { 2 - 3 } PLL- $g$-Dex & $\mathrm{Na}^{+}$ & $\mathrm{K}^{+}$ \\
\hline- & $3.1 \times 10^{8}$ & $1.2 \times 10^{10}$ \\
+ & $2.8 \times 10^{11}$ & $5.0 \times 10^{12}$ \\
\hline
\end{tabular}




\section{Figure legends}

Scheme 1.

Assay for strand exchange reaction of tetramolecular quadruplex.

Scheme 2.

Three possible reaction routes for the strand exchange reaction of tetramolecular quadruplex.

Figure 1.

Structural formula of PLL- $g$-Dex.

Figure 2.

Temperature gradient CD profiles and concentration dependency of $T_{1 / 2}$ of $\left[\mathrm{TG}_{4} \mathrm{~T}\right]_{4}$ quadruplex in absence or presence of PLL-g-Dex. (a) Molar ellipticity at $263 \mathrm{~nm}$ of $\left[\mathrm{TG}_{4} \mathrm{~T}\right]_{4}$ quadruplex in $10 \mathrm{mM} \mathrm{PBS}(\mathrm{pH} 7.2), 100 \mathrm{mM} \mathrm{NaCl}$ at a strand concentration of $500 \mu \mathrm{M} \mathrm{TG}_{4} \mathrm{~T}$ in the absence (black line) or the presence (red line) of PLL- $g$-Dex; spectra were recorded with thermal gradient with $1{ }^{\circ} \mathrm{C} / \mathrm{min}$. Solid and dashed lines indicate heating and cooling profiles, respectively. (b) DNA concentration dependence of $T_{1 / 2}$ of $\left[\mathrm{TG}_{4} \mathrm{~T}\right]_{4}$ in the absence (०) or the presence ( $\bullet$ ) of PLL- $g$-Dex (obtained upon heating).

Figure 3.

Effect of PLL- $g$-Dex on $\mathrm{TG}_{4} \mathrm{~T}$ quadruplex association. The experiments were performed in $10 \mathrm{mM}$ PBS (pH 7.2) containing $100 \mathrm{mM} \mathrm{NaCl}$ or $\mathrm{KCl}$ at $30 \mu \mathrm{M} \mathrm{TG}_{4} \mathrm{~T}$ at $4^{\circ} \mathrm{C}$. (a) Changes in the $\mathrm{CD}$ spectra of $\mathrm{TG}_{4} \mathrm{~T}$ in $100 \mathrm{mM} \mathrm{NaCl}$ in the absence or the presence of PLL- $g$-Dex as a function of time. Dashed lines are $\mathrm{CD}$ spectra of $\mathrm{TG}_{4} \mathrm{~T}$ solution at time $=0$. (b) $k_{\text {on }}$ values at various $\mathrm{N} / \mathrm{P}$ ratios in $100 \mathrm{mM} \mathrm{Na}^{+}$. (c) $k_{\text {on }}$ values at various $\mathrm{N} / \mathrm{P}$ ratios in $100 \mathrm{mM} \mathrm{K}^{+}$. (d) Arrhenius plots of $\mathrm{TG}_{4} \mathrm{~T}$ association rate constant in the absence (०) or the presence $(\bullet)$ of PLL- $g$-Dex (N/P = 2) in $10 \mathrm{mM}$ PBS containing 100 $\mathrm{mM} \mathrm{NaCl}$.

Figure 4.

Effect of PLL or PLL- $g$-Dex on $\mathrm{TG}_{4} \mathrm{~T}$ quadruplex association. The experiments were performed in $10 \mathrm{mM} \mathrm{PBS}(\mathrm{pH} 7.2)$ containing $100 \mathrm{mM} \mathrm{NaCl}$ at $200 \mu \mathrm{M} \mathrm{TG}_{4} \mathrm{~T}$ at $20^{\circ} \mathrm{C}$. DNAs were separated by $20 \%$ non-denaturing acrylamide gel electrophoresis. 
Tetramolecular quadruplexes were stained by ethidium bromide. (a) $\mathrm{TG}_{4} \mathrm{~T}$ alone, (b) $\mathrm{TG}_{4} \mathrm{~T}$ and PLL (N/P = 4), (c) $\mathrm{TG}_{4} \mathrm{~T}$ and PLL- $g$-Dex $(\mathrm{N} / \mathrm{P}=4)$. (d) Time course of quadruplex molar fractions were plotted from the gel electrophoresis experiments;(汭 $\mathrm{TG}_{4} \mathrm{~T},(\boldsymbol{\Delta}) \mathrm{TG}_{4} \mathrm{~T}$ and PLL, $(\bullet) \mathrm{TG}_{4} \mathrm{~T}$ and PLL- $g$-Dex.

Figure 5.

Effect of PLL- $g$-Dex on $\mathrm{TG}_{4} \mathrm{~T}$ quadruplex dissociation. The experiments were performed in $10 \mathrm{mM}$ PBS ( $\mathrm{pH} 7.2$ ) containing $100 \mathrm{mM} \mathrm{NaCl}$ at $7.5 \mu \mathrm{M}\left[\mathrm{TG}_{4} \mathrm{~T}_{4}\right.$ at $60^{\circ} \mathrm{C}$. (a) $k_{\text {off }}$ values at various N/P ratios (b) Arrhenius plots of $\left[\mathrm{TG}_{4} \mathrm{~T}\right]_{4}$ dissociation rate constant in the absence $(\circ)$ or the presence $(\bullet ; N / P=2)$ of PLL- $g$-Dex.

Figure 6.

Strand exchange reaction between $\left[\mathrm{TG}_{4} \mathrm{~T}\right]_{4}$ and $\mathrm{F}-\mathrm{TG}_{4} \mathrm{~T}$ in absence or presence of PLL-g-Dex. $\left[\mathrm{TG}_{4} \mathrm{~T}\right]_{4}\left(55 \mu \mathrm{M}\right.$ strand concentration) was incubated at $25^{\circ} \mathrm{C}$ with $\mathrm{F}^{-\mathrm{TG}_{4} \mathrm{~T}}$ $(20 \mu \mathrm{M})$. a) PAGE images of the reaction mixtures (N/P $=0$ or 4$)$. b) Time courses of the strand exchange reaction at various N/P ratios. Values of $\%$ exchange were quantified from band intensities of $\left[\left(\mathrm{TG}_{4} \mathrm{~T}\right)_{3} \cdot \mathrm{F}-\mathrm{TG}_{4} \mathrm{~T}\right]$.

Figure 7

DNAs binding with the copolymer measured by fluorescence correlation spectroscopy. Either $110 \mathrm{nM} \mathrm{TG} 4$ and $10 \mathrm{nM} \mathrm{F-TG} 4{ }_{4} \mathrm{~T}(\bullet)$ or $30 \mathrm{nM}\left[\left(\mathrm{TG}_{4} \mathrm{~T}\right)_{3} \cdot \mathrm{F}-\mathrm{TG}_{4} \mathrm{~T}\right](\circ)$ were mixed with various concentrations of PLL- $g$-Dex in $10 \mathrm{mM}$ PBS buffer containing 100 $\mathrm{mM} \mathrm{NaCl}$ at room temperature. Samples were analyzed by fluorescence correlation spectroscopy. 


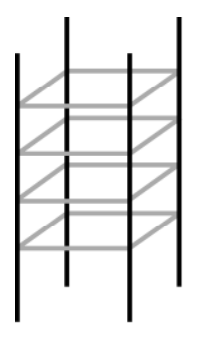

$\left[\mathrm{TG}_{4} \mathrm{~T}\right]_{4}$

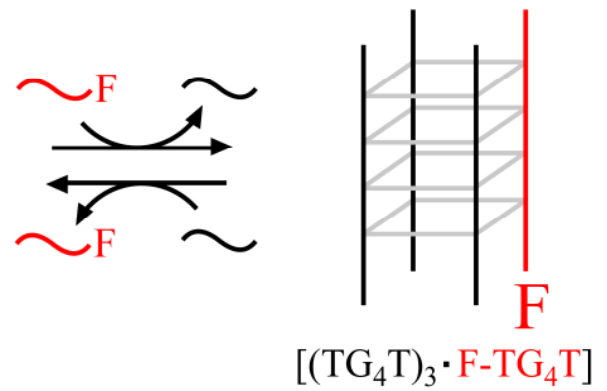

Moriyama et al Scheme 1 
a) Completely dissociative pathway
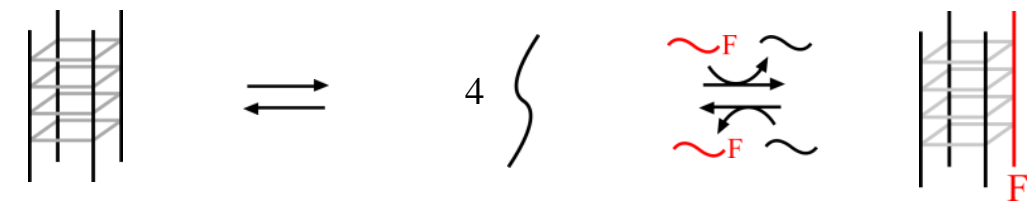

$\left[\mathrm{TG}_{4} \mathrm{~T}\right]_{4}$

$\mathrm{TG}_{4} \mathrm{~T}$

$\left[\left(\mathrm{TG}_{4} \mathrm{~T}\right)_{3} \cdot \mathrm{F}-\mathrm{TG}_{4} \mathrm{~T}\right]$

b) Partially dissociative pathway
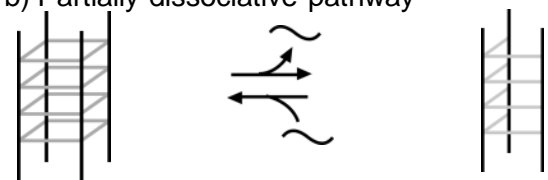

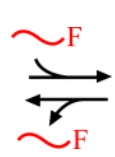

$\left[\mathrm{TG}_{4} \mathrm{~T}\right]_{4}$

$\left[\mathrm{TG}_{4} \mathrm{~T}\right]_{3}$

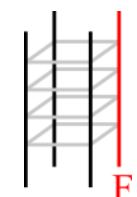

$\left[\left(\mathrm{TG}_{4} \mathrm{~T}\right)_{3} \cdot \mathrm{F}-\mathrm{TG}_{4} \mathrm{~T}\right]$

c) Sequential displacement pathway

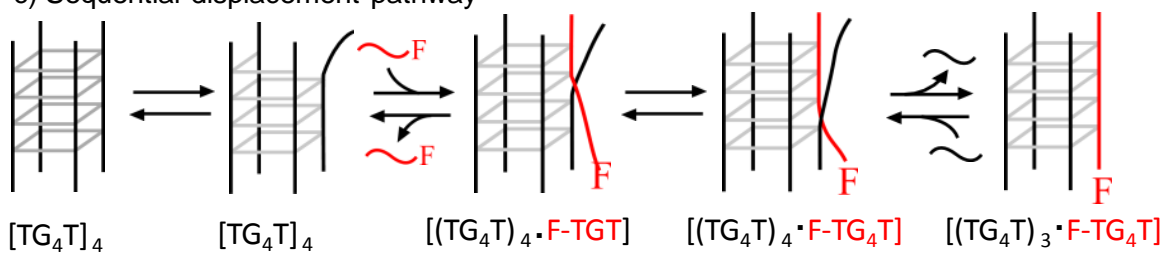

Moriyama et al Scheme 2 


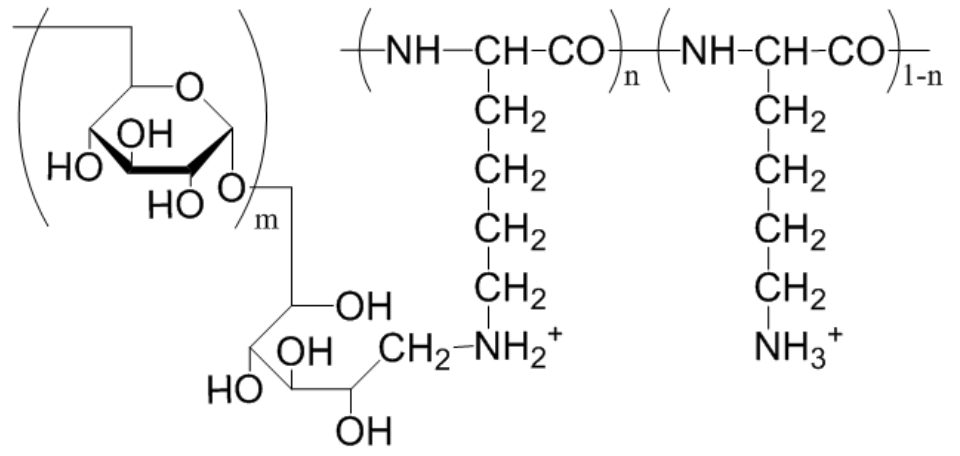

Moriyama et al. Figure 1 
a)

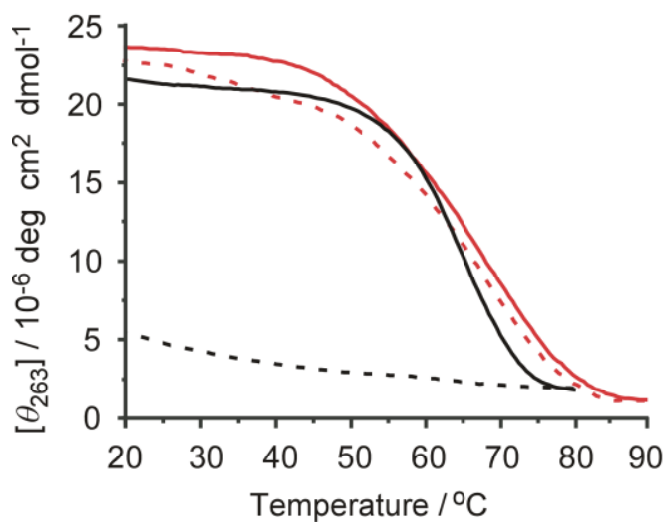

b)

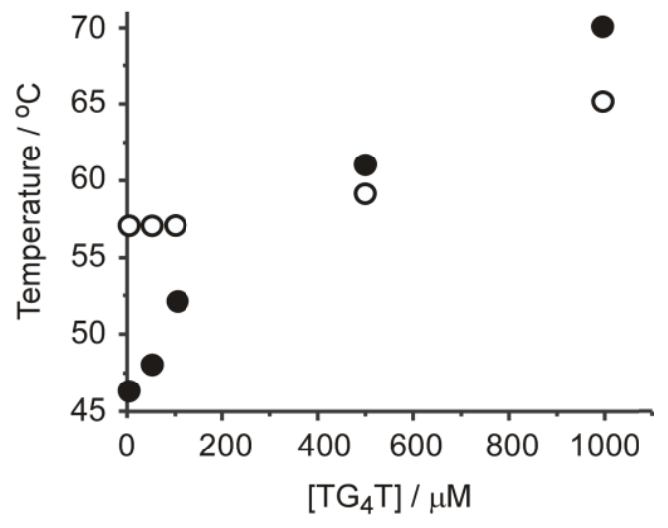

Moriyama et al Figure 2 
a)

$$
\text { PLL-g-Dex (-) }
$$
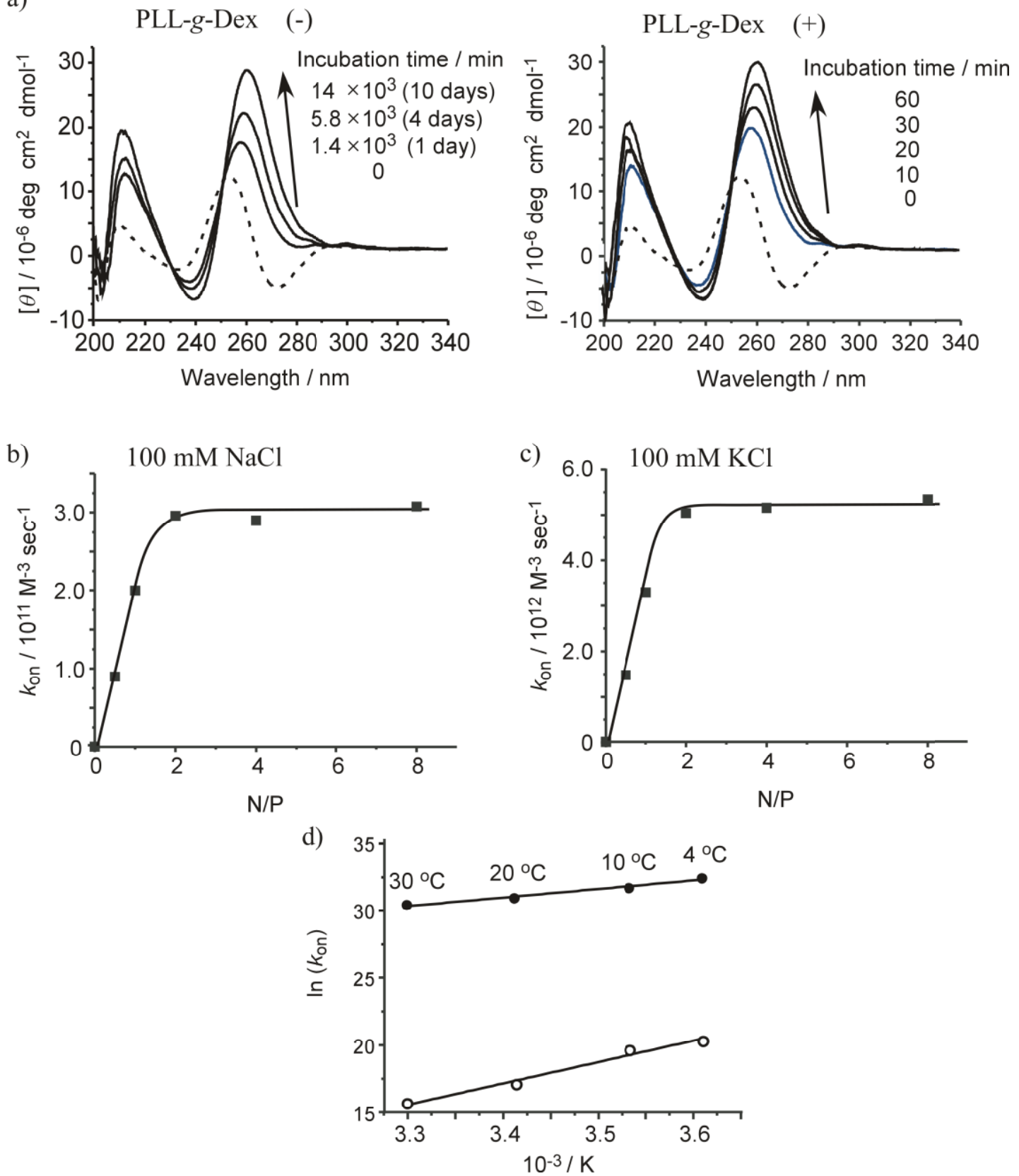

Moriyama et al Figure 3 
a)

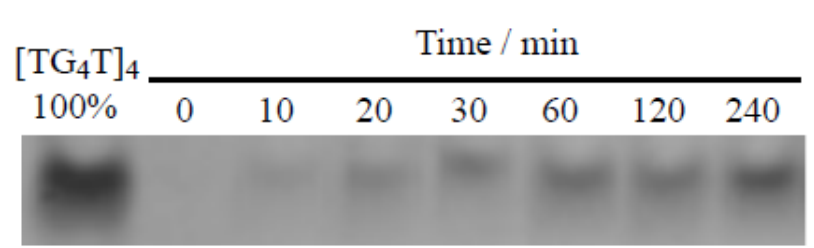

b)

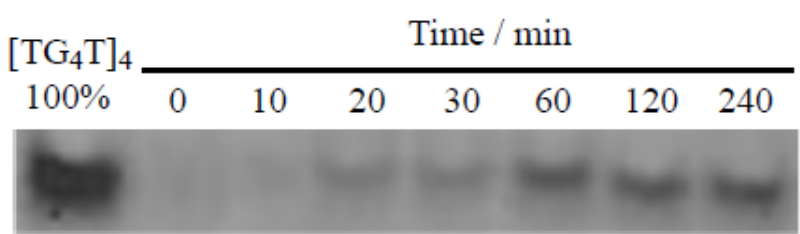

c)

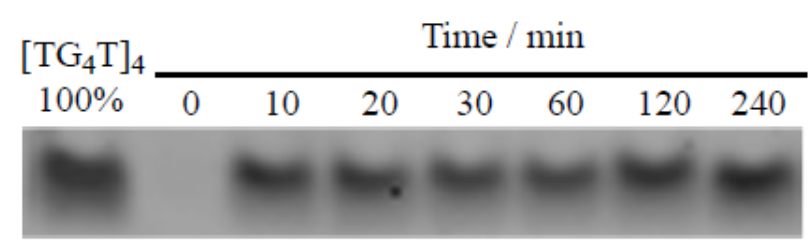

d)

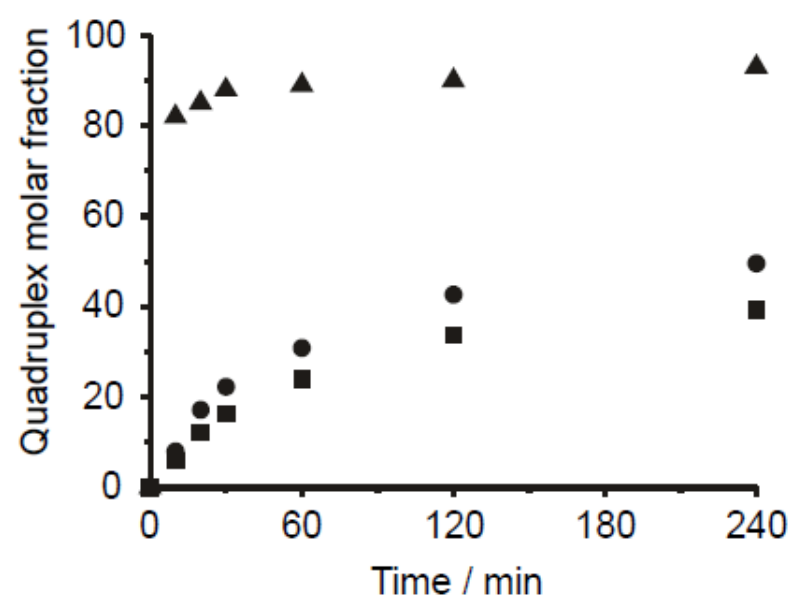

Moriyama et al Figure 4 

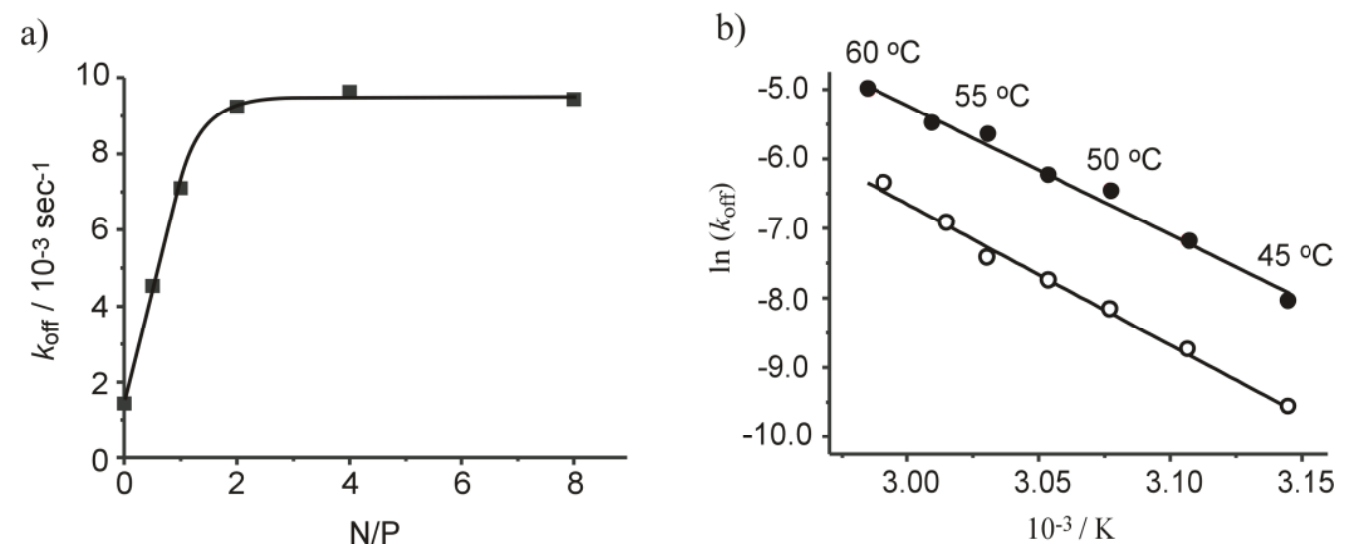

Moriyama et al Figure 5 
a) PLL-g-Dex (-)

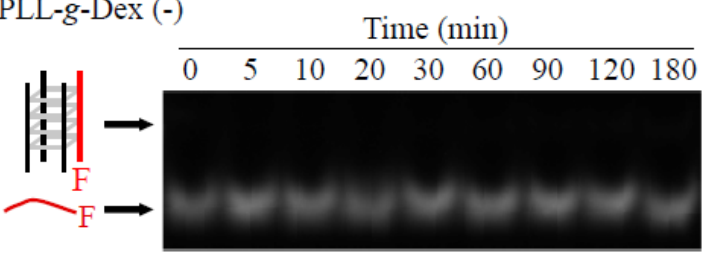

PLL-g-Dex (+)

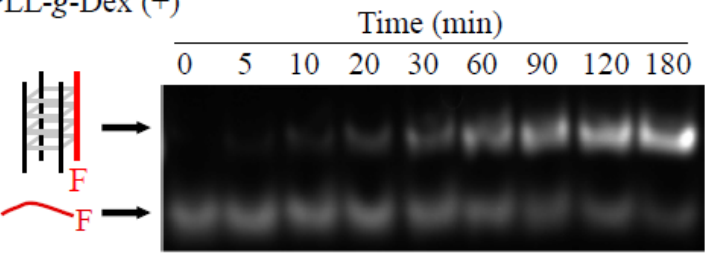

b)

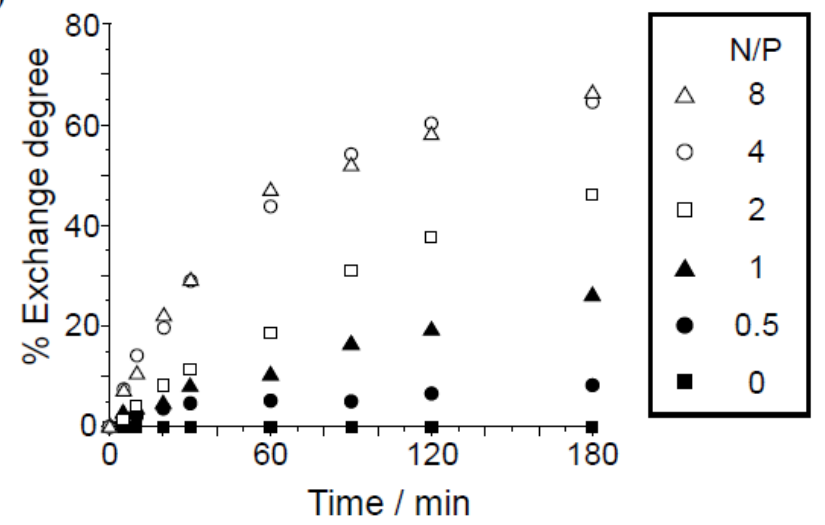

Moriyama et al Figure 6 


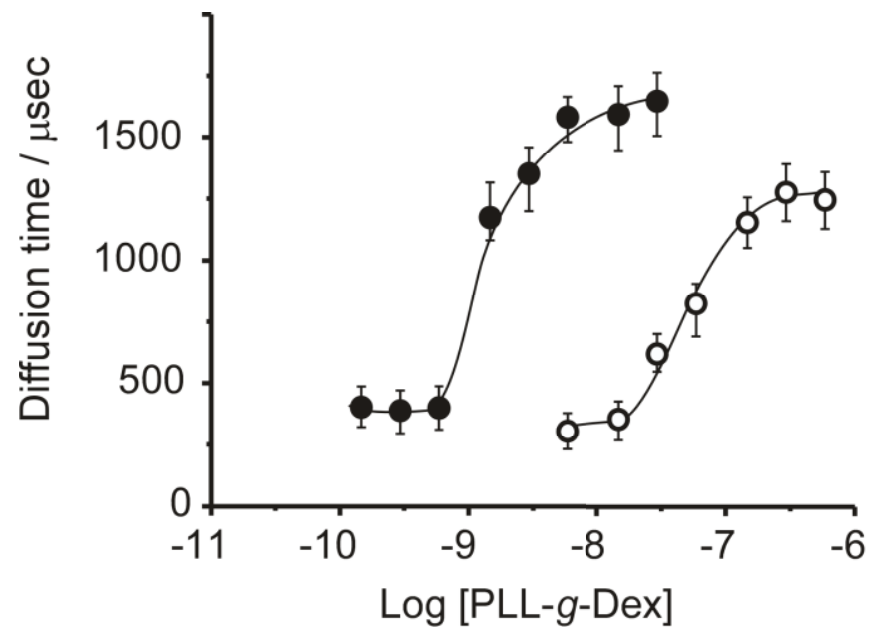

Moriyama et al Figure 7 